\title{
Collection and local use of accident and emergency hospital data in England
}

\author{
Hugh F Thomas, Pauline S A Morgan, Derek Hirst
}

\begin{abstract}
Objective-To obtain information on the collection and local use of accident and emergency data.

Methods-A postal questionnaire was sent to 248 English accident and emergency (A\&E) departments. Responses were obtained from $217(88 \%)$.

Results-Only $87(40 \%)$ of departments were fully computerised, with $109(50 \%)$ using manual systems, and $21(10 \%)$ a mixture of both. Significantly more computerised departments reported that they undertook studies (epidemiological, accident prevention, and resource management) than non-computerised departments. Only limited information on the types of injury studied was provided. The most common topics were childhood accidents, road traffic accidents, and poisonings. Staff in 45 departments $(21 \%)$ reported membership of safety organisations. Around $90 \%$ of departments reported that they notified general practitioners and health visitors of their patients' attendance, usually within $3 \mathrm{~d}$ of the event.

Conclusions-Computerisation appears to help the collection of A\&E data for public health research. There is scope to increase the involvement of public health and other workers in epidemiological studies using A\&E data. A\&E departments should themselves become more involved with local safety organisations.

( $f$ Accid Emerg Med 1996;13:23-25)
\end{abstract}

Key terms: Accident and emergency departments; data collection; accident prevention; epidemiological studies.

The reduction in mortality and morbidity caused by accidents is one of the five key areas in the Health of the Nation White Paper, $A$ strategy for health in England. ${ }^{1}$ The NHS has an important part to play in reducing accidents and their health effects. ${ }^{1-3}$ In practical terms this could be done by including accident prevention as a key element in health promotion, participating in local multiagency schemes (healthy alliances), collecting information on the incidence, causes and severity of accidents, and providing high quality treatment and rehabilitation services. ${ }^{2}$ We have carried out a survey examining the collection and local use of accident and emergency (A\&E) data from English A\&E departments.

Methods

A questionnaire (and up to two reminder letters) was sent to the consultant in charge at
248 English hospitals identified from hospital directories $^{4}{ }^{5}$ as having an A\&E department, and usually seeing over 20000 new patients annually. Details were requested about the information system in use, local studies undertaken, involvement of A\&E staff in local safety activities, and communication with other professional staff.

\section{Results}

Completed replies were received from 217 departments $(88 \%)$. Half $(n=109)$ reported that they still used manual record systems, while $87(40 \%)$ stated that they were computerised. Twenty one departments $(10 \%)$ used a mixture of both methods. For both computer hardware and software there were more than a dozen different systems in use. The commonest software systems in use were produced by ISTEL Ltd $(n=13)$, SMS (13), Footman Walker (12), and CAER Computer Systems (8). Two regions, the South West and Trent, appear to have common software systems, which reports suggested were similar to the ISTEL systems.

Most fully computerised systems ( $n=56$; $64 \%$ ) have been installed since 1990 , and 62 $(71 \%)$ are linked to the main hospital system. Significantly more $\left(\chi^{2}\right.$ test, $\left.P<0.01\right)$ fully or partly computerised departments than manual departments reported that they conducted studies during the last two years on local epidemiology, health promotion and accident prevention, and costing and resource management (table 1)

Only 66 of the 124 departments which reported undertaking epidemiological or accident prevention studies in the last two years gave details of the subjects investigated. These included childhood accidents $(n=16)$, road traffic accidents (11), drugs and ingestions (7), burns and smoke injury (6), other injuries (6), and head injuries (5). Thirty departments indicated who had carried out the studies. They comprised A\&E staff (11), clerks for the Home and Leisure Accident Surveillance Scheme (8), ${ }^{6}$ public health departments (7), health promotion departments (5), and health visitors (5). Almost half of all departments $(n=106 ; 49 \%)$ reported that they were undertaking trauma audit, with $66(30 \%)$ mentioning the major trauma outcome study $(\mathrm{MTOS})^{7}$ and $45(21 \%)$ collaboration with the Salford/Manchester coordinating centre.

Additional data collection to that specified in the A\&E minimum data set, which applies only to computerised systems ${ }^{8}$ (table 2 ), was mentioned by a minority of departments. The main subject listed was ICD ' $\mathrm{E}$ ' codes (International 
Table 1 Number (\%) of studies reported by A\&E departments in the last two years

\begin{tabular}{lll}
\hline Subject & \multicolumn{2}{l}{ Type of information system } \\
\cline { 2 - 3 } & $\begin{array}{l}\text { Manual } \\
(n=109)\end{array}$ & $\begin{array}{l}\text { Fully/partly computerised } \\
(n=108)\end{array}$ \\
\hline Local epidemiology & $41(38)$ & $66(61)^{\star}$ \\
Health promotion/accident prevention & $40(37)$ & $61(56)^{\star}$ \\
Costing/resource management & $28(26)$ & $51(47)^{\star}$ \\
One or more of above studies & $61(56)$ & $85(79)^{\star}$ \\
\hline
\end{tabular}

*Significantly more fully/partly computerised departments reported undertaking studies than those with manual systems. ( $\chi^{2}$ test, $P<0 \cdot 01$ ).

$\mathrm{n}=$ number of departments.
Table 2 Fields of the $A \mathcal{E} E$ minimum data set

\begin{tabular}{l} 
Demographic data \\
Age, sex, postcode \\
Patient group \\
RTA \\
Other accident \\
Deliberate self harm \\
Non-injury \\
Brought in dead \\
Location of incident \\
Home \\
Work \\
Educational establishment \\
Sport \\
Public place \\
Other \\
Diagnosis, investigation, treatment \\
Codes for local developmentpending nationally agreed \\
definitions \\
\hline Source: reference 8.
\end{tabular}

classification of diseases external cause code $)^{9}$ by 43 departments (20\%) (15 all attenders; 28 inpatient only).

Staff in 45 departments $(21 \%)$ reported membership of safety organisations including regional or district accident prevention groups (18), child accident prevention groups (14), and Health and Safety Executive committees (5). Several respondents were members of other bodies such as the Medical Commission on Accident Prevention, the Royal Society for the Prevention of Accidents (RoSPA), and British Standards groups.

Most respondents $(n=155 ; 71 \%)$ reported that they provided safety displays in their departments. Details of A\&E attenders were passed on by departments to general practitioners $(n=202 ; 93 \%)$, health visitors $(n=197 ; 91 \%)$, social services $(n=111 ; 51 \%)$, and paediatricians $(n=103 ; 48 \%)$. Many respondents qualified their reply with the term "as appropriate". Liaison health visitors were mentioned in 31 returns (14\%) and 11 $(5 \%)$ also mentioned geriatric liaison nurses. Communications with general practitioners were reportedly made within $3 \mathrm{~d}$ of attendance by 195 departments $(90 \%)$. Information was sent only through the internal hospital delivery system by 58 departments $(27 \%)$, by a patient delivered letter from 24 departments $(11 \%)$, and by mail from 15 departments $(7 \%)$. The remaining departments used a combination of these methods; four used electronic mail.

\section{Discussion}

This survey obtained a good response $(88 \%)$ from consultants and senior staff in English A\&E departments. The information obtained was self reported practice and this may be subject to reporting errors. No checks were made on the accuracy of the information provided, except to note that $26(93 \%)$ of the 28 respondents known to be participating in a major trauma outcome study ${ }^{7}$ reported this on their returns.

The survey identifies a number of practices which those responsible for purchasing and providing A\&E services should consider. When compared with non-computerised departments, computerised departments reported undertaking significantly more studies related to local injury epidemiology, health promotion and accident prevention, and costing and resource management. This may partially reflect the enthusiasm of the staff, but is more likely to show that computerisation facilitates such studies.

At the time of the survey (the first six months of 1993 ) only 87 departments $(40 \%)$ were fully computerised. Although not specifically asked about future intentions, $33(30 \%)$ of the noncomputerised departments expressed the intention of installing a computerised system. In their general comments $23(21 \%)$ of the fully or partially computerised departments emphasised that adequate resources were required to run such systems.

Details of the different $A \& E$ computer systems in use have been published elsewhere. ${ }^{10}$ The strengths and weaknesses of the different systems were not examined in this study. Standardisation on the type of injury related data would make interdepartmental and geographical comparisons on the incidence, cause, and severity of injuries more reliable. The clinical terms project ${ }^{11}$ should help with this, although there may be difficulties in providing comparative data on injury severity. ${ }^{12}$ The general recording of ICD ' $E$ ' codes (preferably from the 10 th revision) would be a useful first step in the development of a better comparative national injury data system. Further studies are required to establish whether it is practical to collect, within the $\mathrm{A} \& \mathrm{E}$ department, more detailed information on accident location, preceding events, and personal characteristics. ${ }^{13}$

There appears to be scope to increase the involvement of public health and other workers in epidemiological studies using $\mathrm{A} \& \mathrm{E}$ data. A\&E departments that are not presently involved on local safety organisations should also consider whether they could make a useful contribution.

Communication between the A\&E department and other health professionals is reportedly good, with $90 \%$ notification to general practice within three days of $A \& E$ attendance. However, such high levels of prompt communication may not apply to those departments which rely upon patients delivering their letters. Many departments will have to review their method of communicating with general practitioners if purchasing commissions insist on notifications being made within 24 hours of attendance. ${ }^{14}$ It is perhaps questionable whether such prompt communication is necessary for minor cases not requring follow up.

While those surveyed often expressed an interest and willingness to be involved in 
accident prevention, many comments indicated that staff were fully occupied dealing with the annually increasing number of people attending $\mathrm{A} \& \mathrm{E}$ departments for treatment. A few departments had improved their information gathering by using staff involved in trauma and clinical audit to obtain more detailed information on accidents as well. Nevertheless, our impression after studying over 200 questionnaires was that most departments require extra clerical help (full time and part time) to collect and present injury statistics in a locally and nationally useful way.

The recent formation in the United Kingdom of an Intercollegiate Faculty of Accident and Emergency Medicine could provide an opportunity to encourage standardisation of $A \& E$ data collection, improve injury surveillance, and coordinate epidemiological studies.

We are grateful to all those who returned questionnaires, and to Mr Jonathan Marrow for providing technical advice. The Department of Health provided financial support for the study, and we thank Ms Sam Rashbrook for clerical help.

1 Department of Health. The health of the nation: a strategy for health in England. London: HMSO, 1992.
2 Department of Health. Key area handbook - accidents. London: HMSO, 1993.

3 National Association of Health Authorities. The Royal Society for the Prevention of Accidents. Action on accidents - the unique role of the health service. Birmingham: NAHA RoSPA, 1990.

4 Casualty Surgeons Association. Accident and emergency department handbook. Loughborough: CSA, 3M, 1990.

5 CMA Medical Data. The directory of emergency and special care units. Cambridge, CMA Medical Data Ltd, 1991.

6 Consumer Safety Unit (DTI). Home and leisure accident surveillance systems. (Various reports published annually.) London: HMSO.

7 Yates DW, Woodford M, Hollis S. Preliminary analysis of the care of injured patients in 33 British hospitals: first report of the United Kingdom major trauma outcome study. BMJ 1990;305:737-40.

8 NHS Management Executive. AEE minimum data set. Leeds: Information Management Group, 1993.

9 World Health Organisation Manual of the international statistical classification of diseases, injuries and causes of death, vol 1, 9th revision. Geneva: WHO, 1977.

10 British Association for Accident and Emergency Medicine. Clinical Services Study Committee. Register of complinical Services Study Committee. Register of com- $A E^{2}$ records systems. London: BAEM, 1992.

11 NHS Centre for Coding and Classification. Clinical Terms Project. Loughborough: NHS Management Executive, 1994

12 Zolfie N, de Dombal FT (Yorkshire Trauma Audit Group). The hit and miss of ISS and TRISS. BMF 1993;307 906-9.

13 Department of Health. Public Health Information Strategy. Improving information on accidents. (Implementation project 19.) London: Department of Health, 1993.

14 Welsh Health Planning Forum. Protocol for investment in health gain injuries. Cardiff: Welsh Office NHS Directorate, 1992. 